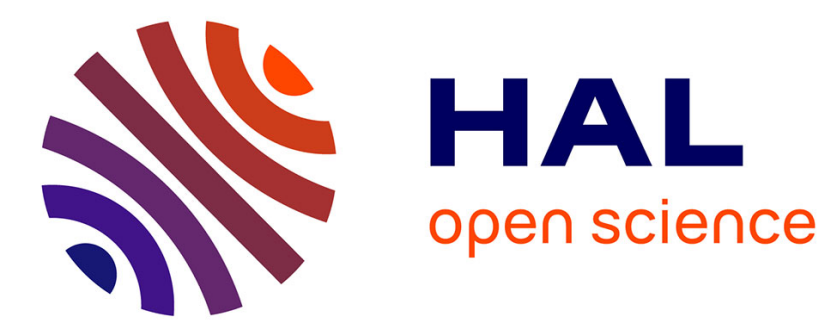

\title{
High-altitude observations of the polar wind
}

T. E. Moore, C. R. Chappell, M. O. Chandler, P. D. Craven, B. L. Giles, C. J. Pollock, J. L. Burch, D. T. Young, J. H. Waite Jr., J. E. Nordholt, et al.

\section{To cite this version:}

T. E. Moore, C. R. Chappell, M. O. Chandler, P. D. Craven, B. L. Giles, et al.. High-altitude observations of the polar wind. Science, 1997, 277 (5324), pp.349-351. 10.1126/science.277.5324.349 . insu-01676904

\section{HAL Id: insu-01676904 https://hal-insu.archives-ouvertes.fr/insu-01676904}

Submitted on 8 Jul 2020

HAL is a multi-disciplinary open access archive for the deposit and dissemination of scientific research documents, whether they are published or not. The documents may come from teaching and research institutions in France or abroad, or from public or private research centers.
L'archive ouverte pluridisciplinaire HAL, est destinée au dépôt et à la diffusion de documents scientifiques de niveau recherche, publiés ou non, émanant des établissements d'enseignement et de recherche français ou étrangers, des laboratoires publics ou privés. 
T. E. Moore, ${ }^{\star}$ C. R. Chappell, $\uparrow$ M. O. Chandler, P. D. Craven, B. L. Giles, C. J. Pollock, J. L. Burch, D. T. Young,

J. H. Waite Jr., J. E. Nordholt, M. F. Thomsen, D. J. McComas, J. J. Berthelier, W. S. Williamson, R. Robson, and F. S. Mozer 


\section{High-Altitude Observations of the Polar Wind}

T. E. Moore, ${ }^{\star}$ C. R. Chappell, $\nmid$ M. O. Chandler, P. D. Craven, B. L. Giles, C. J. Pollock, J. L. Burch, D. T. Young, J. H. Waite Jr., J. E. Nordholt, M. F. Thomsen, D. J. McComas, J. J. Berthelier, W. S. Williamson, R. Robson, F. S. Mozer

Plasma outflows, escaping from Earth through the high-altitude polar caps into the tail of the magnetosphere, have been observed with a xenon plasma source instrument to reduce the floating potential of the POLAR spacecraft. The largest component of $\mathrm{H}^{\text {* flow, }}$ along the local magnetic field ( 30 to 60 kilometers per second), is faster than predicted by theory. The flows contain more $\mathrm{O}$ than predicted by theories of thermal polar wind but also have elevated ion temperatures. These plasma outflows contribute to the plasmas energized in the elongated nightside tail of the magnetosphere, creating auroras, substorms, and storms. They also constitute an appreciable loss of terrestrial water dissociation products into space.

Polar outflows of Earth's ionospheric plasma, or "polar wind," were punningly named (1) by analogy to the solar wind. The ionosphere has an even higher ratio of plasma thermal speed to escape velocity than that of the solar corona. The geomagnetic field is reshaped by the solar wind so that the outer field lines are parted from an inner region in which field lines remain reasonably dipolar. This forms high-latitude regions in which the field lines are stretched antisunward and are either connected into the interplanetary field or closed at large distances from Eurth in the downstream magnetotail. Symmetric north and south vacuum wake regions are known as the magnetospheric "lobes." These are magnetically connected to the polar cap ionospheres, suljecting them to a low-pressure boundary condition and producing a vacuum wake effect. The lohes have low plasma electron density, $<1 \mathrm{~cm}^{-3}$ as judged from plasma wave spectral features (2).

The resultant polar wind has been studied since the late 1960 s, including extensive theory and observations up to 4 Earth radii $\left(R_{\mathrm{t}}\right)$ (3). Direct observation of the polar wind at higher altitudes has been hampered by positive photoelcctric charging of sunlit spacecraft in low-density plasmas (4). This

T. E. Moore, C. R. Chappell, M. O. Chandler, P. D. Craven, B. L. Giles, NASA Marshall Space Flight Center. Huntsville, AL, USA.

C. J. Pollock, J. L. Burch, D. T. Young, J. H. Waite Jr. Southwest Research institute, San Antonio, TX, USA.

J. E. Nordholt, M. F. Thomsen, D. J. McComas, Los Alamos National Laboratories, Los Alamos, NM, USA.

J. J. Berthelier, Centre d'Etudes Terrestraire et Planetaire, St. Maur-des-Fossés, France.

W. S. Wiliamson and R. Robson, Hughes Research Laboratories Malibu, CA, USA.

F. S. Mozer, University of Califomia, Berkeley, CA, USA.

"Present address: NASA Goddard Space Flight Center. Greenbelt, MD 20771, USA.

fPresent address: Vanderbilt University, Nashville, TN 37212, USA. effect excludes ions from reaching a spacecraft floating at an electric potential, relative to the plasma, that is larger than their kinetic energy per charge. It has been estimated that the outflow is alequate to supply the magnerosphere with plasma (5); however, it has been difficult to study the transport of this plasma to greater heights and determine its contribution to the region of particle acceleration and magnetospheric storm magnetosphere at tens of $R_{\mathrm{E}}(6)$.

The Thermal Ion Dynamics Experiment (TIDE) and Plasma Source Instrument (PSI) on the POLAR spacecraft (7) were developed for high ion flux sensitivity and to overcome the spacecraft charging problem, respectively. POLAR was launched 24 February 1996 into a $1.8 R_{\mathrm{E}} \times 8.9 R_{\mathrm{E}}$ polar orhit having a period of about 18 hours. POLAR spins with a period of $6.0 \mathrm{~s}$ about an axis normal to its orhital plane. Its orbit was initially oriented near the noon-midnight meridian, with the ascending node on the dayside.

TIDE (4) measures the velocity distribution of ions once per 6-s spin of the spacecraft. It samples nearly the entire sky at a nominal resolution of $22.5^{\circ}$ (polar) by $11.25^{\circ}$ (spin azimuth) and in the energy range from 0.3 to $500 \mathrm{eV}$ with resolution $\triangle E / E \sim 0.25$. TIDE uses seven apertures, each commandable up to $1 \mathrm{~cm}^{2}$ of effective area. Time-of-flight analysis of each detected particle is used to sort the ion flux by mass per charge with a resolution of $m / \Delta m$ $\sim 2$, which is sufficient to identify the ionospheric species $\mathrm{H}^{+}, \mathrm{He}^{+}, \mathrm{O}^{++}, \mathrm{O}^{+}$, and $\mathrm{NO}^{+}$, as well as the $\mathrm{He}^{++}$thought to be principally of solar origin. PSI (4) is a xenon plasma source that establishes a discharge of $-250 \mathrm{~mA}$ at $20 \mathrm{~V}$ within a xenon gas flow of 0.5 standard $\mathrm{cm}^{3} \mathrm{~min}^{-1}$. The discharge occurs at a potential that is somegeneration known to exist in the tail of the what positive of the source chassis, permitting an ion escape current up to $1 \mathrm{~mA}$, which is much larger than the photocurrent demind of $\sim 25 \mu \mathrm{A}$. A vernier supply hiases the source relative to the spacecraft chassis in the range $\pm 10 \mathrm{~V}$, allowing fine control of the spacccraft potential relative to the plasma. The POLAR floating potential is monitored by the Electric Field Instrument (EFI) (8) on POLAR, by means of three pairs of multiclement probes deployed on orthogonal wire antennas spanning up to $130 \mathrm{~m}$ from tip to tip. In all cases discussed here, PSI operated with a vernier bias setting that regulated the POLAR spacecraft near $+1.8 \mathrm{~V}$, as indicated hy the EFI probes.

During the long POLAR apogee passes, the plasma density reaches low values $(<1$ $\mathrm{cm}^{-3}$ ), the floating potential rises to tens of volts, and often there is litrle or no lowenergy ion plasma seen at all if PSI is off. POLAR often traverses the dayside cleft, which is a localized region where energetic solar plasma is always observed, entering along field lines that connect to the dayside auroral zone. The solar wind density and particle encrgy are sufficient to limit spacecraft charging to a potential that is negligibe relative to the sollar particle characteristic energy. Thus, obscrvations of solar plasmas are unobscured by typical positive charging levels.

Two features of the solar wind plasma entering the cleft [Fig. 1; 14:00 to 14:30 universal time (UT)] are of interest here: (i) the peaking of the $\mathrm{H}^{+}$flux toward the upper end of the TIDE energy range, and (ii) the lack of spin or polar angle variation of the fluxcs. The polat cap itself is typically characterized by the absence of any plasma observable by TIDE. With PSI operating, howcver, a narrow beam (localized in energy, spin azimuth angle, and polar angle) of $\mathrm{H}^{+}$and $\mathrm{O}^{+}$is observed (Fig. 1), persisting throughout this pass. The flux peaks in the middle of the plot energy range (10 to 100 $\mathrm{eV}$ ), with a decreasing trend throughout the pass. The flux peaks in spin azimuth angle near the local magnetic field direction in cach energy sweep of data (minus signs). The green color indicates peak flux near the magnetic field direction in the polar angle, whereas the variation to blue indicates a relative crosswind. Near 23:00 hours, PSI was turned off, and this caused the field aligned flows to disappear, especially for $\mathrm{H}^{\prime}$ (Fig. 1). Thus, the operation of PSI allowed us to observe low-energy plasma that could not he observed because of substantially larger spacecraft floating potentials.

The outflowing plasma velocity distribution (Fig. 2) is (i) quite cool (compared with the entering solar plasma in the cleft), that is, localized to a narrow region of the sampled velocity space; (ii) closely aligned 
with the local magnetic field; and (iii) contains $\mathrm{O}^{+}$with hulk velocity slower than that of the $\mathrm{H}^{+}$. In the cases shown, the thermal speed measured parallel to the mag- netic field is somewhat larger than the thermal speed measured perpendicular to the magnetic field, and both are smaller than the parallel flow speed.

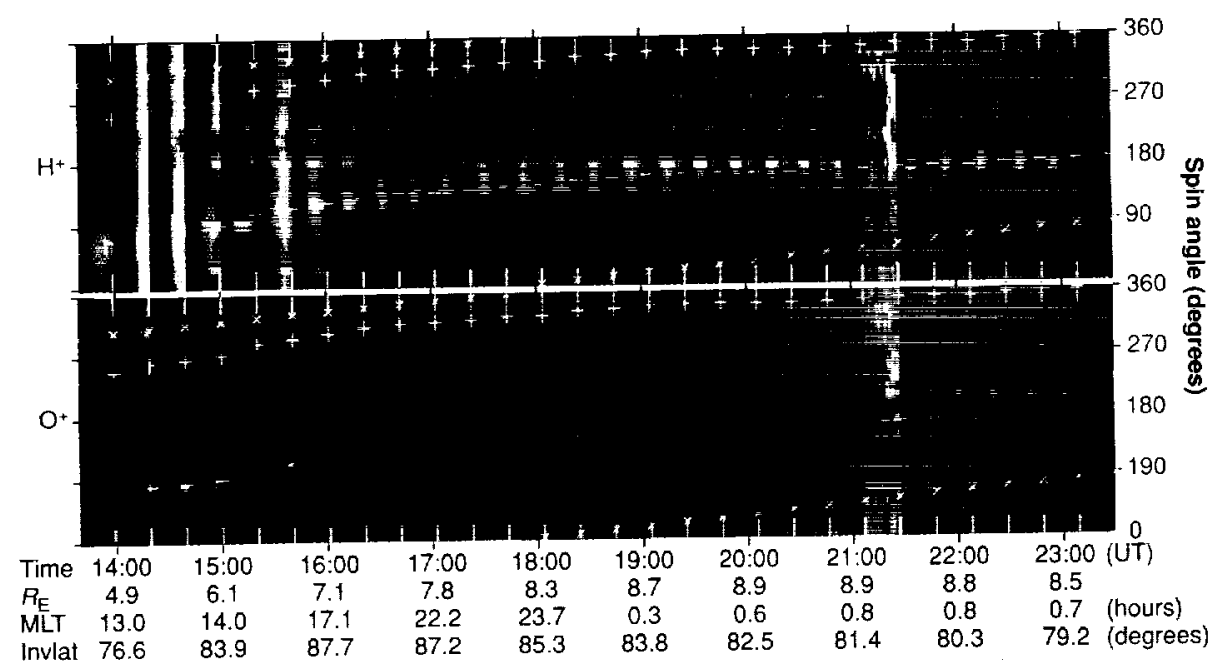

Fig. 1. For $\mathrm{H}^{+}$(upper panel) and $\mathrm{O}^{+}$(lower panel), ion flux data are plotted after averaging over 20-min intervals, which are bounded by white tic marks. Within each interval, the energy flux is color-coded $\left(10^{3}\right.$ to $10^{6} \mathrm{eVs}{ }^{1} \mathrm{~cm}^{-2} \mathrm{sr}^{-1} \mathrm{eV}^{-}$ as indicated by the vertical brightness bar at bottom) versus energy ( 0.4 to $450 \mathrm{eV}$, along the $x$ or time axis), spin azimuth angle $\left(0^{\circ}\right.$ to $360^{\circ}$, along the $y$ or vertical axis), and polar angle

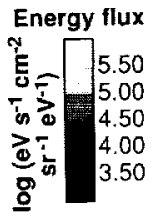

angle $\left(0^{\circ}\right.$ to $360^{\circ}$, along the or $67.5^{\circ}$ to $112.5^{\circ}$, and blue for $112.5^{\circ}$ to $\left.157.5^{\circ}\right)$. No measurements exist in the polar angle range from $157.5^{\circ}$ to $180^{\circ}$. Spacecraft geocentric radius $\left(R_{E}\right)$, magnetic local time (MLT; in hours), and invariant latitude (invlat; in degrees) are indicated along the horizontal axis. The spin angles closest to the magnetic field direction and its opposite are indicated by yellow plus and minus signs, respectively, whereas the spacecraft velocity spin angle is indicated by yellow $x$ 's. The color wheel indicates the interpretation of colors as polar angle distributions (red if peaked at small angles, green if peaked at angles near $90^{\circ}$, blue if peaked at large angles, gray if broadly distributed across the polar angle). Black radial lines in the color wheel indicate the polar angle range of the local magnetic field direction, whereas white radial lines indicate the polar angle range of spacecraft velocity. PSI was on until 23:10 hours, when it was turned off. A background measurement at 21:05 to 21:20 hours produced a data gap.
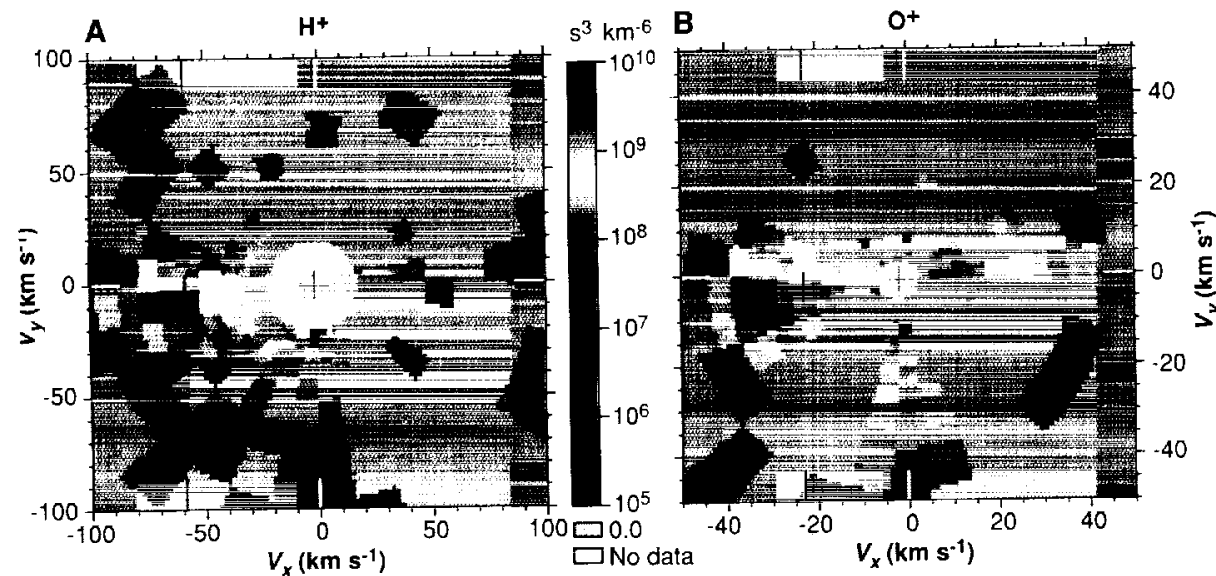

Fig. 2. $H^{\prime}\left(\right.$ A) and $O^{\prime}($ B) velocity $(V)$ distributions are plotted on 19 April 1996 from 16:24:57 to 16:29:54 UT in a plane defined by the local magnetic field ( $x$ axis) and the normal vector lying in the spacecraft orbit plane ( $y$ axis). The phase space density is contoured as indicated by the saturated color bar at center. Tic marks indicate the spacecraft frame of reference (fine black), the Earth frame of reference (white), and the computed plasma frame (bold black). The velocity ranges differ between the $\mathrm{H}^{+}$and $\mathrm{O}^{+}$panels.
Line plots of selected bulk propertics of the distributions (Fig. 3) illustrate the spatio-temporal variations observed during this pass through the polar cap or lobe region. The observed $\mathrm{H}^{+}$densities are in the range 0.1 to $1 \mathrm{~cm}^{-3}$, and the $\mathrm{O}^{+}$densities are smaller, which is consistent with the observed charging of spacecraft in gencral, and specifically with POLAR charging in the absence of PSI operation and in the same region of space, where potentials of 20 to 30 $\mathrm{V}$ are typical. The observed $\mathrm{H}^{+}$density falls in the range between the 8 to $9 R_{E}$ results from two recent models of the polar wind $(9,10)$.

The largest flow component (middle panel, Fig. 3) is the negative flow (upward) opposite to the local magnetic field direction (downwarl). The upward flow magnitude can be seen to fill somewhat ahove the results of Ganguli et al. (9) and is comparable to those of Mitchell et al. (10). The transverse flow (not shown here) is generally antisunward with decreasing magnitude as the pass progresses toward the nightside. There is initially a comparable duskward component that reverses roward dawn in the nightside of the pass. The range of transverse flow speeds (10 to $20 \mathrm{~km} \mathrm{~s}^{-1}$ ), mapped along equipotential field lines, agrees with typical flow speeds observed in the ionosphere $\left(0.5\right.$ to $\left.0.75 \mathrm{~km} \mathrm{~s}^{-1}\right)$.

The plasma temperature (lower panel, Fig. 3) is high and close to isotropic within the solar plasma of the cleft region. It decreases with distance from the dayside auroral zone, more rapidly in the transverse component, so that the temperature is anisotropic in some regions. Toward the end of the pass, the $\mathrm{H}^{+}$remperature falls to a few electron volts, whereas the $\mathrm{O}^{+}$temperature remains ahove $5 \mathrm{eV}$.

The ion flux measurements are assumed to be made from a symmetric spacecraft at a potential of $+1.8 \mathrm{~V}$ with respect to the surrounding plasma. Modest errors are produced by asymmetries of the spacecraft, one of which is the space charge associated with the localized cmission and separation of xenon ions and clectrons from the plasma source instrument. Stray potentials on the order of $0.5 \mathrm{~V}$ are known to exist hetween the electric field instrument probes (100 and $130 \mathrm{~m}$ from tip to tip) when PSI operates. Such potentials deflect particles with the lowest energies $(\angle 5 \mathrm{eV})$, distorting the low-speed parts of the distrihutions somewhat. The errors in the computed moments are primarily in odd (velocity) moments, appearing mainly in the form of small ( $\leq 10 \%$ of the parallel velocity) officts in the transwerse velocity components.

The observed polar plasma outflow is hotter and contains a higher flux of $\mathrm{O}^{+}$ than predicted by thermal outflow theory 
(7). Enhanced $\mathrm{O}^{+}$content has also been noted in lower altitude observations of polar wind, and several theoretical efforts have been made to account for this, invoking a variety of energetic processes, including processes that introduce energy in the electrons (3). The present observations indicate that ion heating plays a significant role. Plasma flux tubes flow through a known region of plasma heating in the dayside auroral zone (11), just before their subsequent flow antisunward across the polar cap. Nonthermal effects have only rarely and incompletely been incorporated into models of terrestrial plasma transport (12, 13), but it appears that they influence the character of the entire polar cap outflow region.

Polar plasma outflows have been cited as sources of the plasma sheet by several observers (14-17) who interpreted their data as field-aligned streams of $\mathrm{H}^{+}$and $\mathrm{O}^{+}$in varying mixtures, traveling at essentially the same velocity independent of mass. Typical flow parameters (17) for the $\mathrm{H}^{+}$are 0.02 to $0.05 \mathrm{~cm}^{-3}$ and 100 to $200 \mathrm{~km} \mathrm{~s}^{-1}$; that is, the fluxes have higher velocity and lower density but are similar to the fluxes reported here. Although the $\mathrm{O}^{+}$is certainly of ionospheric origin, there is considerable uncertainty and interest in the ionospheric region of $\mathrm{O}^{+}$origin (dayside or nightside auroral oval, or polar cap) and in the origin of the $\mathrm{H}^{+}$, which could be from the solar wind but arrives as a cold stream that is more characteristic of an ionospheric source.

The polar plasma outflows reported here are the same as the cold plasma streams that flow into the plasma sheet from the polar lobes, providing a supply of plasma of variable composition and energy. However, additional acceleration is required between the high-altitude polar cap and the distant plasma sheet. Near the distant lobe-plasma sheet boundary, this acceleration may have raised the $\mathrm{H}^{+}$energy enough to be seen by instruments on unneutralized spacecraft.

These observations can be used to estimate the total flux of plasma ions escaping from Earth to the magnetotail through the polar caps. If we take the typical outflow speed to be $40 \mathrm{~km} \mathrm{~s}^{-1}$ and the typical density to be $0.3 \mathrm{~cm}^{-3}$, and assume the radius of the area through which the outflow exists to be $4 R_{E}$ (the region above $60^{\circ}$
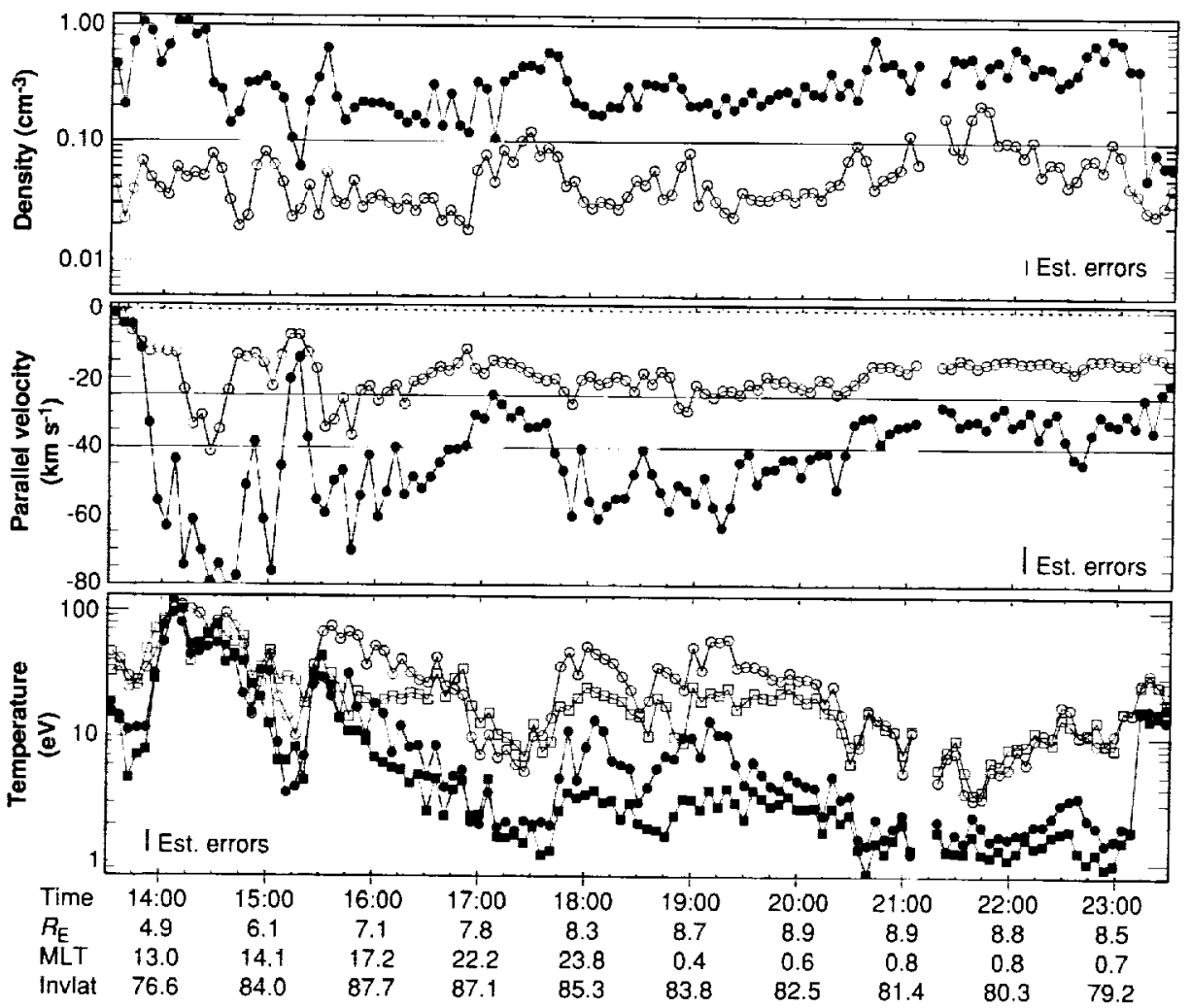

Fig. 3. $\mathrm{H}^{+}$(solid symbols) and $\mathrm{O}^{+}$(open symbols) moments, including density, velocity along the local magnetic field, and the temperatures parallel (circles) and perpendicular (squares) to the local magnetic field, are plotted at 5 -min intervals. Comparisons with theory are indicated by horizontal bars. Error estimates are represented by vertical bars. PSI was on until $23: 10$ hours, when it was turned off. A background measurement at 21:05 to 21:25 hours produced a data gap. MLT is measured in hours; invariant latitude is measured in degrees. geomagnetic latitude, at $8 R_{\mathrm{E}}$ geocentric distance), the rate of ourflow is $-2.5 \times$ $10^{25} \mathrm{H}^{+}$per second. At $20 \mathrm{~km} \mathrm{~s}^{-1}$ and 0.05 $\mathrm{cm}^{-3}$, the $\mathrm{O}^{+}$is much smaller in number flux but exceeds the mass flux of $\mathrm{H}^{+}$. If the $\mathrm{O}^{+}$content is produced by auroral plasma heating processes, it may be anticipated that this will increase with geomagnetic and solar activity (18). The total outflow mass flux at low solar and genmagnetic activity is similar to known accretion fluxes of dust and meteorites.

These obscrvations of Earth's polar plasma fountains show that polar wind outflows continue to accelerate into the lobes of the magnetosphere, supplying the near-Earth plasma sheet of the geotail. Otiginating from a region of space that has previously been characterized as empty or devoid of plasma, these observations show that this region is filled with supersonic ionospheric outflows traveling along the local geomagnetic field. The observed high-altitude flows include $O^{\prime}$ fluxes in excess of polar wind theory (3) but also at higher temperature. The presence of hot heavy ions in these outflows demonstrates that existing models of the polar wind require generalization to at least two dimensions so as to include the results of plasma tube circulation through regions subject to ion heating by nonthermal auroral processes.

\section{REFERENCES AND NOTES}

1. W. I. Axford, J. Geophys. Res. 73, 6855 (1968)

2. A. M. Persoon, D. A. Gurnett, S. D. Shawhan, ibid. 88, 123 (1983).

3. S. B. Ganguli, Rev. Geophys. 34, 311 (1996).

4. T. E. Moore et al., Space Sci. Rev. 71, 409 (1995).

5. C. R. Chappell, T. E. Moore, J. H. Waite Jr., J. Geo phys. Res. 92, 5896 (1987).

6. R. A. Kerr, Science 242, 377 (1988).

7. M. H. Acuña et al., Space Sci. Rev. 71, 5 (1995).

8. P. J. Harvey et al., ibid., p. 583.

9. S. B. Ganguli, H. G. Mitchell Jr, P. J. Palmadesso, Planet. Space Sci. 35, 703 (1987)

10. H. G. Mitchell Jr., S. B. Ganguli, P. J. Palmadesso, J Geophys. Res. 97, 12045 (1992)

11. C. J. Pollock et al., ibid. 95, 18969 (1990).

12. J. H. Whitteker, Flanet. Space Sci. 25, 773 (1977).

13. J. L. Horwitz and M. Lockwood, J. Geophys. Res. $90,9749(1985)$.

14. L. A. Frank, K. L. Ackerson, D. M. Yeager, ibid. 82 129 (1977).

15. M. Candidi, S. Orsini, J. L. Horwitz, ibid. 93, 14401 (1988).

16. T. Mukai et al., Geophys. Res. Lett. 21, 1023(1994)

17. M. Hirahara et al., J. Geophys. Res. 101, 7769 (1996).

18. A. W. Yau, W. K. Peterson, E. G. Sheltey, Geophys. Monogr. Ser. 44, 211 (1988).

19. This paper is dedicated to the memory of Dr. W. B. Hanson, whose insights and leadership were pivotal in the design of TIDE. Supported by the NASA Global Geospace Science Program at Goddard Space Flight Center, by NASA grant NAG5-3182 at the University of California, and by the NASA Office of Space Flight at the Marshall Space Flight Center. The authors are indebted to the technical staffs of their institutions for development of the TIDE and PSI hardware and software.

6 February 1997; accepted 30 May 1997 